\title{
Penentuan Lokasi Bandara Udara di Kabupaten Lamongan
}

\author{
Ramadhan Tirta Saputra dan Sardjito \\ Jurusan Perencanaan Wilayah dan Kota, Fakultas Teknik Sipil dan Perencanaan, Institut Teknologi \\ Sepuluh Nopember (ITS) \\ Jl. Arief Rahman Hakim, Surabaya 60111 Indonesia \\ e-mail: sardjito24@yahoo.com
}

\begin{abstract}
Abstrak-Seiring dengan adanya AFTA pada tahun 2015 mendatang program ASEAN Open Sky juga akan diselenggarakan di langit ASEAN. ASEAN Open Sky adalah situasi dari ekstensifikasi liberalisasi pada region ASEAN. Yang menjadi salah satu alasan dari adanya ASEAN Open Sky ini adalah untuk meningkatkan kompetisi dari industri penerbangan, dan memberikan seluruh maskapai kesempatan untuk bersaing di seluruh rute di dalam ASEAN. Sebagai salah satu solusi dalam menghadapai AFTA dan ASEAN Open Sky adalah dengan memperbesar kapasitas bandara atau membangun bandara baru. Pemerintah Provinsi Jawa Timur sendiri sudah memikirkan hal tersebut dengan menuangkan rencana dalam RTRW Provinsi Jawa Timur 2011-2031. Selain pada dokumen RTRW, pembangunan bandar udara di Kabupaten Lamongan juga telah dimasukkan dalam dokumen Tataran Transportasi Wilayah Provinsi Jawa Timur (Tatrawil) tahun 2012-2032 yang juga sudah di Perda-kan. Oleh karena itu perlu untuk menentukan lokasi bandar udara di Kabupaten Lamongan. Penelitian ini menggunakan tiga alat analisis yaitu teknik analisa delphi, AHP (Analytical Hierarchy Process), dan Overlay. Teknik analisa delphi digunakan untuk mengkonfirmasi variabel-variabel yang mempengaruhi dalam penentuan lokasi di Kabupaten Lamongan. Teknik analisa AHP digunakan untuk mencari bobot dari tiap variabel dalam mempengaruhi penentuan lokasi di Kabupaten Lamongan. Pada proses analisa overlay, digunakan metode weighted sum yang dibantu dengan software Arcgis 10.1 sehingga muncul lokasi lahan yang paling sesuai dengan kriteria yang telah dibentuk. Dari analisa yang telah dilakukan ditemukan bahwa lokasi lahan yang mempunyai nilai sesuai berada diantara Kecamatan Solokuro dan Kecamatan Paciran. Dengan kordinat antara $112^{\circ} 20^{\prime} 01.3571^{\prime \prime} E 6^{\circ} 53^{\prime} 57.9336^{\prime \prime} S, 112^{\circ} 23^{\prime} 21.7230^{\prime \prime}$ $E \quad 6^{\circ} \quad 52^{\prime} \quad 21.6192 \quad " S, \quad 112^{\circ} 26^{\prime} 47,39^{\prime \prime} E \quad 6^{\circ} 53^{\prime} 17,068^{\prime \prime} S$, $112^{\circ} 23^{\prime} 34,345^{\prime \prime} E 6^{\circ} 57^{\prime} 20,207^{\prime \prime} S$.
\end{abstract}

Kata Kunci- AHP; Bandar Udara;Delphi;Overlay.

\section{PENDAHULUAN}

$\mathrm{P}$ ADA kawasan strategis

pengembangan Gerbangkertasusila, Kota Surabaya yang menjadi pusat pertumbuhan dilayani oleh Bandar udara Internasional Juanda. Sebagai gerbang utama pada jalur udara Bandar udara Internasional Juanda selalu mengalami kenaikan jumlah penerbangan dalam melakukan pelayanan. Akan tetapi dampak dari adanya kegiatan bandar udara ini masih belum bisa dimaksimalkan oleh daerah lain selain Kota Surabaya di Wilayah Provinsi Jawa Timur. Bisa dilihat dari adanya disparitas pembangunan. terminal udara atau bandar udara ini dapat digunakan sebagai alat untuk menanggulangi disparitas pendapatan antar daerah. [1]

Seiring dengan adanya AFTA pada tahun 2015 mendatang program ASEAN Open Sky juga akan diselenggarakan di langit ASEAN. Program ini juga memberikan maskapai penerbangan flexibilitas dalam mengembangakan rute perjalanan.[2] Adanya Open Sky ini dipastikan akan semakin meramaikan lalu lintas penerbangan yang ada di Indonesia karena makin banyaknya maskapai yang beroperasi dari regional ASEAN.

Sebagai salah satu solusi dalam menghadapai AFTA dan ASEAN Open Sky adalah dengan memperbesar kapasitas bandara atau membangun bandara baru. Pemerintah Provinsi Jawa Timur sendiri sudah memikirkan hal tersebut dengan menuangkan rencana dalam RTRW Provinsi Jawa Timur 2011-2031. Dalam dokumen rencana tersebut dituliskan bahwa terdapat rencana pembangunan bandar udara baru di Kabupaten Lamongan. Selain pada dokumen RTRW, pembangunan bandar udara di Kabupaten Lamongan juga telah dimasukkan dalam dokumen Tataran Transportasi Wilayah Provinsi Jawa Timur (Tatrawil) tahun 2012-2032 yang jugas sudah di Perda-kan. Pada salah satu pasalnya disebutkan bahwa adanya pengembangan bandara internasional di kawasan Pantura Jawa Timur untuk mendukung percepatan pertumbuhan KPI-Lamongan dan KPIGresik, mengurangi kongesti dan over capacity Bandara Juanda.

Wilayah tanpa bandar udara atau pelayanan bandar udara yang kurang maksimum akan terbatasi kapasitas berkembangnya [3]. Selain itu rencana pengembangan bandar udara baru di Kabupaten Lamongan dalam RTRW Jatim belum ditentukan lokasinya. Karena itu perlu adanya penelitian lokasi bandar udara di Kabupaten Lamongan

\section{METODE PENELITIAN}

\section{A. Metode Pengumpulan data}

Dalam mengerjakan penelitian ini, digunakan metode survei yaitu sekunder dan primer. Srurvei primer diakukan melalui observasi lapangan secara langsung ataupun dengan melakukan wawancara. Sedangkan survei sekunder dilakukan 
dengan menggunakan dokumen-dokumen yang terdapat pada instansi pemerintahan seperti Bappeda Kabupaten Lamongan, Dinas PU Ciptakarya Kabupaten Lamongan, dsb

\section{B. Metode Analisis}

\section{Identifikasi Kriteria dan variabel yang Berpengaruh Dalam Penentuan Lokasi Bandar Udara}

Pada tahap ini peneliti bertujuan untuk merumuskan kriteria-kriteria yang berpengaruh dalam penentuan lokasi bandar udara. Sebelumnya peneliti sudah melakukan sintesa pustaka terhadap beberapa teori dan juga peraturan yang ada. di Indonesia sendiri penentuan lokasi bandar udara sudah diatur dalam Peraturan Mentri Perhubungan No. 20 Tahun 2014. Hasil sintesa yang akan dihasilkan akan menjadi input dalam analisa delphi

Dalam menggunakan alat analisa delphi dibutuhkan beberapa pakar yang relevan dengan permasalahan yang akan dijawab dalam penelitian ini. Setiap pakar akan menjadi narasumber untuk mengkonfirmasi variabel yang berpengaruh dalam penentuan lokasi bandar udara. Analisa delphi dapat dikatakan berhasil apabila semua pendapat dari narasumber telah mencapai konsensus. Apabila pendapat dari narasumber belum mencapai konsensus maka diperlukan iterasi (pengurangan) hingga tercapai konsensus [4].

\section{Penentuan Lokasi Bandar Udara di Kabupaten Lamongan}

Dalam menentukan lokasi bandar udara, agar hasil yang didapatkan maksimal maka diperlukan dua alat analisis yaitu AHP (Analytical Hierarchy Process) dan weighted overlay. Analisis AHP digunakan untuk mendapatkan bobot dari masing-masing variabel yang sudah dikonfirmasi oleh para pakar[5]. Tiap variabel perlu dibobotkan untuk menjadi input dalam analisis weighted overlay. Analisis weighted overlay merupakan analisis untuk menghasilkan output lokasi bandar udara di Kabupaten Lamongan. Penliti pada penelitian ini menggunakan software Arcgis 10.1 untuk melakukan proses weighted overlay

\section{HASIL DAN PEMBAHASAN}

\section{A. Gambaran Umum Wilayah Penelitian}

Wilayah Kabupaten Lamongan berada pada sisi pesisisr utara Provinisi Jawa Timur. Sebanyak 462 Desa dan 12 Kelurahan yang tergabung dalam 27 Kecamatan .Luasan wilayah Kabupaten Lamongan sendiri adalah 181.280 Ha. Adapun batas wilayah Kabupaten Lamongan sendiri adalah sebagai berikut :
- Sebelah Utara
- Sebelah Selatan
: Laut Jawa
- Sebelah Timur
: Kabupaten Jombang
- Sebelah Barat

B. Kriteria dan Variabel yang berpengaruh dalam penentuan lokasi Bandar Udara

Pada tahap pertama ini akan dilakukan analisa delphi untuk merumuskan kriteria dan variabel yang berpengaruh terhadap

tujuan dari penelitian ini yang dalam hal ini adalah penentuan lokasi bandar udara di Kabupaten Lamongann. Responden yang diminta pendapatnya pada penelitian ini adalah dari Bappeprov Provinsi Jawa Timur, PT.Angkasa Pura I, Dinas Perhubungan Jawa Timur, Bappeda Kabupaten Lamongan, dan Praktisi.

Wawancara yang dilakukan terhadap responden untuk mengetahui pendapat dari responden dilakukan dengan metode semi terstruktur, dimana responden diminta pendapatnya secara langsung mengenai persetujuan dan pemahaman terhadap kriteria ataupun variabel yang diujikan. Setelah dilakukan proses analisa dan melakukan iterasi maka didapati beberapa kriteria dan variabel yang disetujui konsensus oleh para responden. Kriteria dan variabel tersebut adalah :

- Kriteria Kelayakan Pengembangan Wilayah dengan variabel Kesesuaian dengan RTRW Nasional, Provinsi, Kabupaten dan Kesesuaian dengan dokumen Tataran Transportasi Nasional, Wilayah dan Lokal

- Kriteria Kelayakan Teknis Pembangunan dengan variabel Kemiringan Lahan, Kemampuan drainase Lahan, Meteorologi, Kestabilan Pondasi Tanah, Jenis Tanah, Infrastruktur, dan Jaringan Utilitas

- Kriteria Kelayakan Lingkungan dengan variabel Lingkungan Alam, Peruntukkan Lahan, dan Penguasaaan Lahan.

- Kriteria Kelayakan Sosial dengan variabel Relokasi Penduduk, Kecocokan dengan budaya setempat

\section{Pembobotan Kriteria dan Variabel dalam penentuan lokasi bandar udara}

Pembobotan dilakukan untuk mengetahui prioritas tiap kriteria dan variabel yang digunakan dalam menentukan lokasi bandar udara di Kabupaten Lamongan. Untuk menentukan bobot dari masing-masing kriteria dan variabel digunakan alat analisis AHP (Analytical Hierarchy Process) dengan menggunakan metode pairwise individual (dibantu software expert choice 11).

Berikut adalah hasil pembobotan dari kriteria dan variabel yang akan dimasukkan dalam proses overlay.

Tabel 1.

Hasil Pembobotan Kriteria dan Variabel Lokasi Bandar Udara

\begin{tabular}{|c|c|c|}
\hline Kriteria & Variabel & $\begin{array}{c}\text { Kombinasi } \\
\text { Bobot }\end{array}$ \\
\hline Kriteria & $\begin{array}{c}\text { Kesesuaian } \\
\text { dengan } \\
\text { RTRW } \\
\text { Nasional, } \\
\text { Provinsi, } \\
\text { Kabupaten }\end{array}$ & 0,08 \\
\hline $\begin{array}{c}\text { Kelayakan } \\
\text { Pengembangan } \\
\text { Wilayah }\end{array}$ & $\begin{array}{c}\text { Kesesuaian } \\
\text { dengan } \\
\text { dokumen } \\
\text { Tataran } \\
\text { Transportasi } \\
\text { Nasional, } \\
\text { Wilayah dan } \\
\text { Lokal }\end{array}$ & 0,07 \\
\hline
\end{tabular}




\begin{tabular}{|c|c|c|}
\hline Kriteria & Variabel & $\begin{array}{c}\text { Kombinasi } \\
\text { Bobot }\end{array}$ \\
\hline \multirow{7}{*}{$\begin{array}{l}\text { Kriteria } \\
\text { Kelayakan } \\
\text { Teknis }\end{array}$} & $\begin{array}{l}\text { Kemiringan } \\
\text { Lahan, }\end{array}$ & 0,05 \\
\hline & $\begin{array}{c}\text { Kemampuan } \\
\text { Drainase }\end{array}$ & 0,09 \\
\hline & $\begin{array}{l}\text { Meteorologi/ } \\
\text { curah hujan }\end{array}$ & 0,14 \\
\hline & $\begin{array}{c}\text { Kestabilan } \\
\text { Pondasi } \\
\text { Tanah } \\
\end{array}$ & 0,14 \\
\hline & Jenis Tanah & 0,07 \\
\hline & Infrastruktur & 0,05 \\
\hline & $\begin{array}{c}\text { Jaringan } \\
\text { Utilitas }\end{array}$ & 0,04 \\
\hline \multirow{3}{*}{$\begin{array}{c}\text { Kriteria } \\
\text { Kelayakan } \\
\text { Lingkungan }\end{array}$} & $\begin{array}{c}\text { Lingkungan } \\
\text { Alam }\end{array}$ & 0,07 \\
\hline & $\begin{array}{c}\text { Peruntukkan } \\
\text { Lahan }\end{array}$ & 0,05 \\
\hline & $\begin{array}{c}\text { Penguasaaan } \\
\text { Lahan. }\end{array}$ & 0,03 \\
\hline \multirow[b]{2}{*}{$\begin{array}{c}\text { Kriteria } \\
\text { Kelayakan } \\
\text { Sosial }\end{array}$} & $\begin{array}{c}\text { Relokasi } \\
\text { Penduduk }\end{array}$ & 0,07 \\
\hline & $\begin{array}{c}\text { Kecocokan } \\
\text { dengan } \\
\text { budaya } \\
\text { setempat }\end{array}$ & 0,05 \\
\hline
\end{tabular}

Dari tabel bisa dilihat bahwa antar variabel memiliki nilai bobot yang tersendiri sehingga sudah mencukupi untuk dilanjutkan pada proses yang selanjutnya yaitu overlay.

\section{Penentuan lokasi Bandar Udara di Kabupaten Lamongan}

Untuk menentukan lokasi bandar udara di Kabupaten Lamongan digunakan metode weighted overlay. Analisis ini digunakan untuk menggabungkan peta-peta tematis yang sesuai dengan variabel yang telah didapat. Penggabungan petapeta tersebut menggunakan bobot AHP yang telah didapatkan pada langkah sebelumnya.

Secara umum penggunaan metode weighted overlay terdiri dari 2 langkah yaitu melakukan reclassify terhadap masingmasing variabel sehingga memliki kisaran nilai yang sama. Langkah selanjutnya adalah melakukan running program GIS dan akan muncul peta kesesuaian lahan yang akan menunjukkan lokasi paling sesuai sebagai Bandar Udara Kabupaten Lamongan. Berikut adalah peta kesesuaian bandar udara Kabupaten Lamongan:

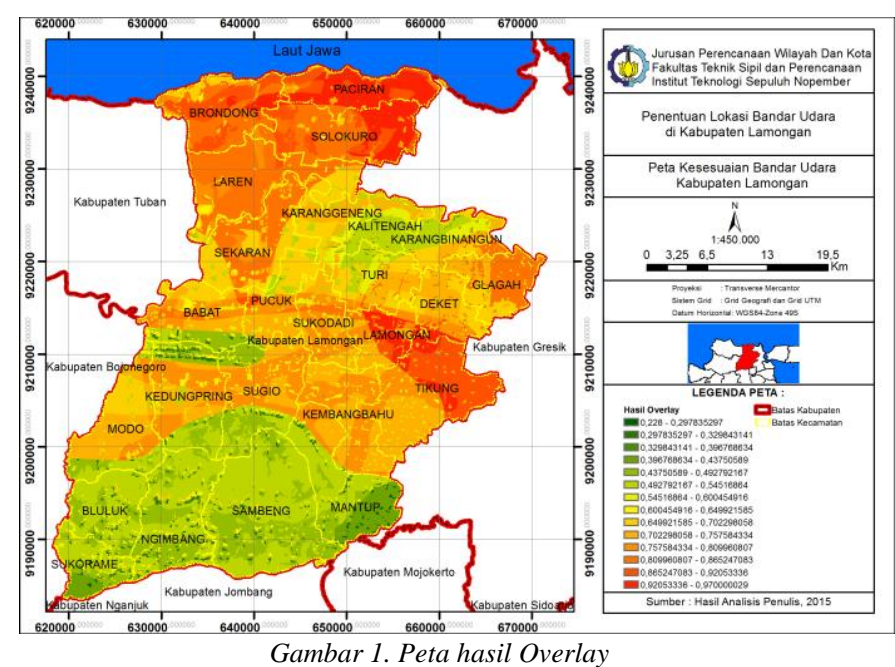

Warna merah pada peta diatas menggambarkan kesesuian lahan paling tinggi, sedangkan warna hijau menggambarkan nilai yang rendah. Nilai paling tinggi yang didapat berada pada daerah utara yaitu berada pada Kecamatan Solokuro dan Paciran.

\section{KESIMPULAN}

Berdasarkan hasil analisa overlay yang didapat adalah lokasi kesesuaian bandar udara berada di antara Kecamatan Paciran dan Kecamatan Solokuro dengan koordinat $112^{\circ} 20^{\prime}$ 01.3571" E $6^{\circ} 53^{\prime} 57.9336 " \mathrm{~S}, 112^{\circ} 23^{\prime} 21.7230^{\prime \prime} \mathrm{E} 6^{\circ} 52^{\prime}$ 21.6192 "S, 112 $26^{\prime} 47,39 " \mathrm{E} 6^{\circ} 53^{\prime} 17,068^{\prime \prime} \mathrm{S}, 112^{\circ} 23^{\prime} 34,345^{\prime \prime} \mathrm{E}$ $6^{\circ} 5720,207 " \mathrm{~S}$.

\section{UCAPAN TERIMA KASIH}

Penulis R.T.S mengucapkan terimakasih kepada Jurusan Perencanaan Wilayah dan Kota atas ilmu yang diberikan dari tahun 2011-2016. Penulis juga diperkenankan menyampaikan ucapan terima kasih kepada Pemerintah Kabupaten Lamongan dan Provinsi Jawa Timur beserta narasumber lainnya atas bantuan data primer dan sekunder dalam penelitian in

\section{DAFTAR PUSTAKA}

[1] Looney, Robert E \& Winterford, David. 1992.The Role of Infrastructure in Pakistan Economic Development. Pakistan Economic And Social Review.

[2] Forsyth, Peter. King, John. Rodolfo, Cherrt Lyn. Trace, Keith. 2004. Preparing For Open Sky : AADCP Regional Economic Policy Support Facility Research Project 02/008. Monash International Pty Ltd

[3] Horonjeff, Robert, 2004. Planning and design of airports.Mcgraw hill, Inc. USA

[4] Dunn, W. N., 2000. Pengantar Analisis Kebijakan Publik. 2nd ed. Yogyakarta: Gadjah Mada University Press

[5] Marimin., 2004, Teknik dan Aplikasi Pengambilan Keputusan Kriteria Majemuk, Gramedia, Jakarta. 